\title{
Methodological developments in the use of visible reflectance spectroscopy for discriminating pasture-fed from concentrate- fed lamb carcasses
}

\author{
P. H. M. Dian ${ }^{1}$, D. Andueza ${ }^{1}$, C. M. P. Barbosa ${ }^{3}$, S. Amoureux ${ }^{1}$, M. Jestin ${ }^{1}$, \\ P. C. F. Carvalho ${ }^{3}$, I. N. Prado ${ }^{2}$ and S. Prache ${ }^{1 \dagger}$ \\ ${ }^{1}$ Institut National de la Recherche Agronomique, INRA, UR1213 Herbivores, Site de Theix, F-63122 Saint-Genès-Champanelle, France; ${ }^{2}$ Universidade Estadual de \\ Maringá, UEM, Av. Colombo 5790, 87020-900, Bloco 32- Sala 3, Maringá-PR, Brazil; ${ }^{3}$ Universidade Federal do Rio Grande do Sul, UFRGS, Av. Bento Gonçalves \\ 7712, CEP 91501-970, CX. Postal 776, Porto Alegre-RS, Brazil
}

(Received 15 February 2007; Accepted 6 June 2007)

\begin{abstract}
The ability to authenticate the feed given to animals from the animal products has become a major challenge for scientists, monitoring bodies and commercial entities alike. This study compared two methods based on the use of the visible reflectance spectrum of the fat to discriminate pasture-fed (P) from stall concentrate-fed (S) lamb carcasses. A total of 307 (143 P and 164 S) Limousine lambs were used over 2 years. Pasture-fed lambs grazed a permanent pasture that was maintained at a leafy, green vegetative stage, and offered ad libitum; they received no supplementation at pasture. Body weight of $P$ lambs when turning out to pasture and at slaughter averaged 9.2 (standard deviation (s.d.) 2.21) $\mathrm{kg}$ and 33.2 (s.d. 2.89) $\mathrm{kg}$, respectively. $\mathrm{S}$ lambs were fed indoors on an ad libitum diet of commercial concentrate and hay until slaughter at a mean body weight of 33.7 (s.d. 3.62) kg. The reflectance spectrum of perirenal and subcutaneous caudal fat was measured at slaughter and at $24 \mathrm{~h}$ post mortem. Plasma carotenoid concentration was measured at slaughter. In method 1, the fat reflectance spectrum data were used at wavelengths between 450 and $510 \mathrm{~nm}$ to calculate an index quantifying light absorption by carotenoid pigments. In method 2, a multivariate analysis was performed over the full set of fat reflectance data at wavelengths between 400 and $700 \mathrm{~nm}$. Method 2 yielded a higher proportion of correctly classified lambs compared with method 1 ( $P<0.05$ to 0.001 ), except for measurements made at $24 \mathrm{~h}$ post mortem on perirenal fat for $\mathrm{S}$ lambs. The proportion of lambs correctly classified using method 2 was $87.4 \%$ and $92.9 \%$ for measurements made on perirenal and caudal fat at slaughter, and $93.9 \%$ and $91.0 \%$ for measurements made on perirenal and caudal fat $24 \mathrm{~h}$ post mortem. Plasma carotenoid concentrations were higher in $P$ lambs than in $S$ lambs $(\mathbb{P}<0.001)$, which led to correct classification of $90.7 \%$ of the lambs.
\end{abstract}

Keywords: authentication, carotenoids, pasture feeding, reflectance, sheep

\section{Introduction}

Recent research (Enser et al., 1998; Nürnberg et al., 2001; Aurousseau et al., 2004) has demonstrated that meat from pasture-fed ruminants has a healthier fatty acid composition than meat from animals fed concentrate diets. Furthermore, consumers are demanding clear information on the food supplied to animals and increasingly focusing on the 'green image' of animal products (Prache and Thériez, 1999). It is therefore important to be able to discriminate between products obtained through different

\footnotetext{
†E-mail: sophie.prache@clermont.inra.fr
}

production systems, in particular, pasture feeding $v$. stall feeding.

Recently, efforts have been made to develop analytical tools to quantify specific compounds in the product or the animal tissues that can act as tracers of the type of food given to animals (Martin et al., 2005; Prache et al., 2005).

Carotenoid pigments have been shown to be good biomarkers of pasture feeding in sheep (Prache and Thériez, 1999; Prache et al., 2002; Priolo et al., 2002). Plasma carotenoid concentration has been successfully used to discriminate between pasture-fed and stall-fed lambs (Prache et al., 2003a), and Prache and Thériez (1999) had proposed a mathematical analysis of the reflectance spectrum of the fat at wavelengths between 450 and $510 \mathrm{~nm}$ (i.e. the zone of 
light absorption by carotenoids) to quantify the signature of these pigments and discriminate pasture-fed from stall-fed lamb carcasses. A measurement of the reflectance spectrum of the fat is actually of obvious practical interest since it is non-invasive, takes little time and can easily be implemented in the meat industry with a portable spectrophotometer.

However, using the full data set of optical information contained in the fat reflectance spectrum, i.e. all the reflectance data at wavelengths between 400 and $700 \mathrm{~nm}$, may provide further valuable information and better discrimination than only using the fat reflectance data at wavelengths between 450 and $510 \mathrm{~nm}$. The purpose of this study was therefore to compare two spectral methods using a portable spectrophotometer, by assessing their reliability in terms of discriminating between carcasses from pasturefed or concentrate-fed lambs (1) using the quantification of light absorption by carotenoid pigments at wavelengths between 450 and $510 \mathrm{~nm}$ and (2) using the full data set of optical information provided by the visible reflectance spectrum at wavelengths between 400 and $700 \mathrm{~nm}$. The interactions with the site of measurements (perirenal $v$. subcutaneous caudal fat) and the time elapsed between slaughter and measurement ( $0 \mathrm{~h} \mathrm{v.} 24 \mathrm{~h}$ post mortem) were investigated, since these factors may affect carotenoid concentration and the spectral characteristics of the fat (Kirton et al., 1975; Priolo et al., 2002).

\section{Material and methods}

This study was carried out over 2 years (2004-05) at the Unité Expérimentale des Mont Dore, Site d'Orcival, an experimental farm run by the Clermont-Ferrand/Theix INRA Centre in France. The animals were handled by specialised personnel who cared for animal welfare in line with European Union directive no. 609/1986.

\section{Animals, diets and slaughter procedures}

A total of 307 Limousine-breed lambs were used; 143 were pasture-fed (group P, 81 males and 62 females) and 164 were stall-fed (group S, 86 males and 78 females). One hundred and thirty-four lambs were slaughtered in 2004 (43 $\mathrm{S}$ and $91 \mathrm{P}$ ) and 173 lambs were slaughtered in 2005 (121 S and $52 \mathrm{P}$ ).

The pasture-fed lambs were born in April (over 4 to 24 April 2004 and 6 to 24 April 2005, except for one lamb that was born on 17 May 2005). They were offered ad libitum a permanent pasture from 3 May in 2004 and from 12 May in 2005 until slaughter, which occurred between 4 August and 4 November in 2004 and between 17 August and 3 November in 2005.

The same pasture was used in both years. It was maintained at a leafy, green vegetative state. Its botanical composition (Table 1) was visually assessed in July 2005 following the method described by Daget and Poissonnet (1971). The presence and the specific volume of each
Table 1 Botanical composition of the pasture grazed by pasture-fed lambs (\% of total biomass)

\begin{tabular}{lr}
\hline \hline Taraxacum sp. & 37.9 \\
Trifolium repens & 29.0 \\
Dactylis glomerata & 8.3 \\
Bromus hordeaceus ssp. Hordeaceus & 6.0 \\
Lolium perenne & 4.9 \\
Elymus repens & 3.9 \\
Poa trivialis & 1.8 \\
Agrostis capillaries & 1.2 \\
Rumex crispus & 1.0 \\
Poa pratensis & 0.8 \\
Ranunculus acris & 0.8 \\
Veronica chamaedrys & 0.8 \\
Rumex obtusifolius & 0.8 \\
Cerastium fontanum ssp. Triviale & 0.7 \\
Heracleaum sphondylium & 0.7 \\
Holcus lanatus & 0.4 \\
Holcus mollis & 0.2 \\
Cruciata laevipes & 0.2 \\
Rumex acetosa & 0.2 \\
Alopecurus pratensis & 0.2 \\
Trifolium pratense & 0.1 \\
Trisetum flavescens & 0.1 \\
\hline \hline
\end{tabular}

species was recorded at 300 points located on 12 transects that were located in areas representative of the paddock vegetation, with 25 points set, $1.0 \mathrm{~m}$ apart on each transect. For each point, an abundance score was given for each species present, so that the sum of all scores at each point equalled 6 . The proportion of each species in relation to total biomass was then calculated as the ratio of the sum of the scores for each species divided by the sum of all scores. The lambs weighed 9.2 (standard deviation (s.d.) 2.21) kg, when at a mean age of 22 (s.d. 6.5) days they were turned out to pasture, except for one lamb that was born at pasture. They were weaned on 26 July in 2004 and on 25 July in 2005. Pasture-fed lambs received no supplementation at pasture.

Stall-fed lambs were given ad libitum indoor access to commercial concentrate and hay. The composition of the concentrate offered is given in Table 2. The stall-fed lambs slaughtered in 2004 were born between 28 November 2003 and 22 April 2004, while those slaughtered in 2005 were born between 13 November 2004 and 24 April 2005. Samples of the hay and concentrate offered to the animals were taken twice weekly to assess carotenoid concentration.

Water and salt blocks were made constantly available in both feeding treatments. Lambs were slaughtered when they had reached a target condition score of 3 (on a scale of 0 to 5), which was manually assessed by skilled technicians according to the method described by Russel et al. (1969). Animals were transported to the abattoir by truck. The abattoir was located within $25 \mathrm{~km}$ of the pasture and the stall. Immediately after their arrival at the slaughterhouse, the animals were electrically stunned and slaughtered by throat cut. The carcasses were placed in a chiller set at 
Table 2 Composition of the concentrate dispensed to stall-fed lambs (g/kg, as-fed basis)

\begin{tabular}{lr}
\hline \hline Components & \\
\hline Barley & 350.5 \\
Soya-bean meal & 141.0 \\
Dried sugar-beet pulp & 110.0 \\
Wheat & 100.0 \\
Sunflower meal & 79.0 \\
Wheat red shorts & 50.0 \\
Maize red shorts & 31.0 \\
Maize & 60.0 \\
Sugar cane molasses & 27.0 \\
Calcium carbonate & 17.0 \\
Lignin & 10.0 \\
Minerals and vitamins & 8.0 \\
Rape seed oil & 7.0 \\
Ammonium chloride & 5.0 \\
Salt & 4.0 \\
Aroma & 0.5 \\
\hline
\end{tabular}

$4^{\circ} \mathrm{C}$ until $24 \mathrm{~h}$ post mortem, and they were always kept in the dark.

\section{Measurements}

Animal characteristics at slaughter. The lambs were weighed just before slaughter. Carcass weight was measured $24 \mathrm{~h}$ post mortem. The perirenal fat and the kidneys were then removed from the cold carcass. The fat was separated from the kidneys using a knife and then weighed. Subcutaneous fat thickness was measured at $24 \mathrm{~h}$ post mortem by making two incisions through the fat along lines extending $4 \mathrm{~cm}$ ventro-laterally from the dorsal mid-line at the last rib and, at the limit of that cut, extending $4 \mathrm{~cm}$ cranially. A flap of fat was raised and subcutaneous fat thickness was measured at the intersection of the incisions (Fisher and De Boer, 1994).

Reflectance spectrum of perirenal and subcutaneous caudal fat. The reflectance spectrum of perirenal and subcutaneous caudal fat was measured on all lambs at wavelengths between 400 and $700 \mathrm{~nm}$, using a MINOLTA CM-2002 spectrophotometer (D65 illuminant, observer angle $10^{\circ}$ ). The instrument was equipped with a protective glass visor to protect the eye of the apparatus from the fat sample. This spectrophotometer measures the proportion of light reflected at 10 -nm intervals at wavelengths between 400 and $700 \mathrm{~nm}$, and records the corresponding reflectance spectrum. Measurements were made in triplicate, at slaughter and at $24 \mathrm{~h}$ post mortem. For the measurements made on perirenal fat $24 \mathrm{~h}$ post mortem, a knife was used to obtain a flat surface so that the fat would adhere perfectly to the eye of the apparatus.

Methods used to discriminate pasture-fed from stall-fed lamb carcasses. In method 1, the fat reflectance spectrum data were used at wavelengths between 450 and $510 \mathrm{~nm}$ to calculate an index quantifying light absorption by carotenoid pigments in the fat. This index was measured as follows. The reflectance spectrum was translated to give a reflectance value at $510 \mathrm{~nm}$ of zero (TR). On the translated spectrum, the integral value $\left(I_{450-510}\right)$ was calculated as follows:

$$
\begin{aligned}
I_{450-510,} \mathrm{TR} \cdot \mathrm{nm}= & {[(\operatorname{TR} 450 / 2)+\operatorname{TR} 460+\operatorname{TR} 470} \\
& +\operatorname{TR} 480+\operatorname{TR} 490+\operatorname{TR} 500 \\
& +(\operatorname{TR} 510 / 2)] \times 10 .
\end{aligned}
$$

The integral value was averaged over the three measurements, then linear discriminant analysis was performed, followed by a cross-validation procedure to classify the fat samples according to feeding treatment, using Minitab software v.13 (Minitab Inc., Paris).

In method 2, the reflectance spectrum of the fat was explored further, by using the full reflectance data set at wavelengths between 400 and $700 \mathrm{~nm}$ to discriminate $\mathrm{P}$ lambs from $\mathrm{S}$ lambs. The reflectance data $(R)$ at wavelengths between 400 and $700 \mathrm{~nm}$ were averaged over the three replicates, then transformed $(\log (1 / R))$ and exported into Win ISI II version 1.5 software (Infrasoft International, Port Matilda, PA, USA) for multivariate analysis. The raw reflectance spectra of each tissue representing the two feeding treatments were submitted to discriminant analysis using a partial least squares discriminant analysis (PLS-DA) approach. PLS-DA consists of a PLS regression where the dependent variable is a set of categorical variables describing the different classes of observations. Each sample was assigned a dummy dependent variable according to feeding treatment (1 for P lambs, 2 for $S$ lambs), using a cut-off value of 1.5 to classify samples according to the feeding treatment. A principal component analysis (PCA) performed beforehand was used to rank the reflectance spectra from each feeding treatment according to the Mahalanobis distance $(H)$ to the average reflectance spectrum, in order to detect sample outliers $(H>3)$. No outliers were found. The models were tested via a cross-validation procedure, in which 66 randomly chosen samples were temporally removed from the initial data set to be used for validation (i.e. a quarter of all data samples). The PLS-DA model was developed based on the other samples (calibration samples) and used to classify the validation samples. This procedure was repeated four times, i.e. until all data set samples had been used through the validation procedure. The cross-validation error of the models was calculated.

Carotenoid concentration in feed. Carotenoids were extracted from concentrate and hay using the procedure described by Cardinault et al. (2006). Lipophilic components of $50 \mathrm{mg}$ of lyophilised and ground food were first extracted with acetone and then purified with diethyl ether containing 
echinenone as internal standard. After being saponified and rinsed with water, the carotenoids were then analysed by high-performance liquid chromatography (HPLC) as described by Lyan et al. (2001). The HPLC apparatus consisted of a Waters Alliance 2996 HPLC system with photodiode array detector monitoring between 280 and $600 \mathrm{~nm}$. Carotenoids were separated on a $150 \times 4.6 \mathrm{~mm}, \mathrm{RP} C 18,3 \mu \mathrm{m}$ Nucleosil column coupled with a $250 \times 4.6 \mathrm{~mm}$, RP C18, $5 \mu \mathrm{m}$ Vydac TP 54 column (Interchim, Montluçon, France). Millenium 32 software published by Waters SA (SaintQuentin-en-Yvelines, France) was used for instrument control, data acquisition and data processing. Detection wavelength for carotenoids was $450 \mathrm{~nm}$, and the compounds were identified by comparing retention times and spectral analyses with those of pure standards $(>95 \%)$. Concentrations of each compound were calculated using external standard curves and were then adjusted by per cent recovery of the added internal standard.

Crude estimation of total plasma carotenoids. Blood was obtained from all lambs on the day before slaughter in order to measure plasma carotenoid concentration. Blood samples were taken from the jugular vein of each lamb in the morning, and the plasma was stored at $-20^{\circ} \mathrm{C}$ until assay. Carotenoids were extracted from the plasma within 3 months after sampling.

A crude estimation of total carotenoids in the plasma was obtained by a spectrophotometric procedure using the following method. Protein from $3 \mathrm{ml}$ of plasma diluted with $2 \mathrm{ml}$ of distilled water was precipitated with $4 \mathrm{ml}$ of ethanol. Carotenoids were then extracted with $4 \mathrm{ml}$ of hexane. Absorption of the upper layer obtained after centrifugation at $5000 \times \mathbf{g}$ for $5 \mathrm{~min}$ was measured between 600 and $400 \mathrm{~nm}$ using a Kontron Uvikon 860 spectrophotometer (Kontron Instruments S. A., Montigny-le-Bretonneux, France). The concentration of total carotenoids was calculated from absorption maxima (Karijord, 1978), assuming a value of 2500 for the E1\% extinction coefficient (Patterson, 1965; Karijord, 1978) and allowing for the dilution of the original sample. Care was taken throughout the experimental and analytical procedure to protect samples from natural light (tubes wrapped in aluminium foil to keep light out, and extraction under dim artificial light). Linear discriminant analysis was performed followed by a cross-validation procedure to classify the plasma samples according to feeding treatment, using Minitab software v.13 (Minitab Inc., Paris).

\section{Statistical analysis}

Animal performances from birth to slaughter, carcass characteristics, $I_{450-510}$ and plasma carotenoid concentration were subjected to analysis of variance using the GLM procedure of the Statistical Analysis Systems Institute (SAS, 1999) software suite to compare feeding treatments. Variances in $I_{450-510}$ and plasma carotenoid concentration were stabilised beforehand using logarithmic transformation.

The proportion of correctly classified carcasses was analysed using the CATMOD procedure of the SAS (1999) software suite using a four-factor model (feeding treatment - pasture $v$. stall feeding -; discrimination method used in the fat - method $1 v$. method 2 -; site of measurement perirenal $v$. subcutaneous caudal -; and time of measurement - slaughter v. $24 \mathrm{~h}$ post mortem), with repeated measures on the three last factors. The individual animal was considered as the statistical unit.

\section{Results}

Animal performances from birth to slaughter and carcass characteristics for $\mathrm{P}$ and $\mathrm{S}$ lambs are given in Table 3 .

For $\mathrm{P}$ lambs, the duration of the grazing period averaged 143 days (s.d. 28.3), ranging from 94 to 187 days. Carotenoid concentrations in the concentrate and hay fed to $S$ lambs were 4.3 and $43.6 \mu \mathrm{g} / \mathrm{g}$ dry matter, respectively (Table 4).

\section{Plasma carotenoid concentration}

Plasma carotenoid concentration at slaughter (PCCS) was higher for $P$ than for $S$ lambs $(P<0.001)$. Plasma carotenoid concentration averaged 75 (standard deviation (s.d.) 33.2) $\mu \mathrm{g} / \mathrm{l}$ for P lambs, ranging from 27 to $194 \mu \mathrm{g} / \mathrm{l}$,

Table 3 Animal performances and carcass characteristics: mean and s.d.

\begin{tabular}{lccc}
\hline \hline Variable & $\begin{array}{c}\text { Pasture-fed } \\
\text { lambs }\end{array}$ & $\begin{array}{c}\text { Stall-fed } \\
\text { lambs }\end{array}$ & Significance $^{+}$ \\
\hline Number & 143 & 164 & \\
Birth weight $(\mathrm{kg})$ & $4.04(0.667)$ & $3.73(0.753)$ & $P<0.001$ \\
Live weight at & $33.2(2.89)$ & $33.7(3.62)$ & $\mathrm{NS}$ \\
$\quad$ slaughter (kg) & & & \\
Age at slaughter (days) & $165(28.1)$ & $111(17.6)$ & $P<0.001$ \\
Average daily gain & $180(40.0)$ & $276(48.9)$ & $P<0.001$ \\
from birth to slaughter & & & \\
$\quad$ g/day) & & & \\
Cold carcass weight (kg) & $14.34(1.608)$ & $15.83(1.835)$ & $P<0.001$ \\
Perirenal fat weight (g) & $264(105.8)$ & $296(145.0)$ & $P<0.05$ \\
Dorsal fat thickness (mm) & $2.5(0.84)$ & $3.5(0.96)$ & $P<0.001$ \\
\hline \hline
\end{tabular}

${ }^{\dagger} \mathrm{NS}=$ non-significant.

Table 4 Carotenoid concentrations ( $\mu \mathrm{g} / \mathrm{g}$ dry matter) of the feed offered to stall-fed lambs

Total

Lutein $\beta$-carotene Zeaxanthin Epilutein carotenoids

\begin{tabular}{lrrrrr}
\hline Concentrate & 4.3 & 0.0 & 0.0 & 0.0 & 4.3 \\
Hay & 33.7 & 0.0 & 7.2 & 2.8 & 43.6 \\
\hline \hline
\end{tabular}


Dian, Andueza, Barbosa, Amoureux, Jestin, Carvalho, Prado and Prache

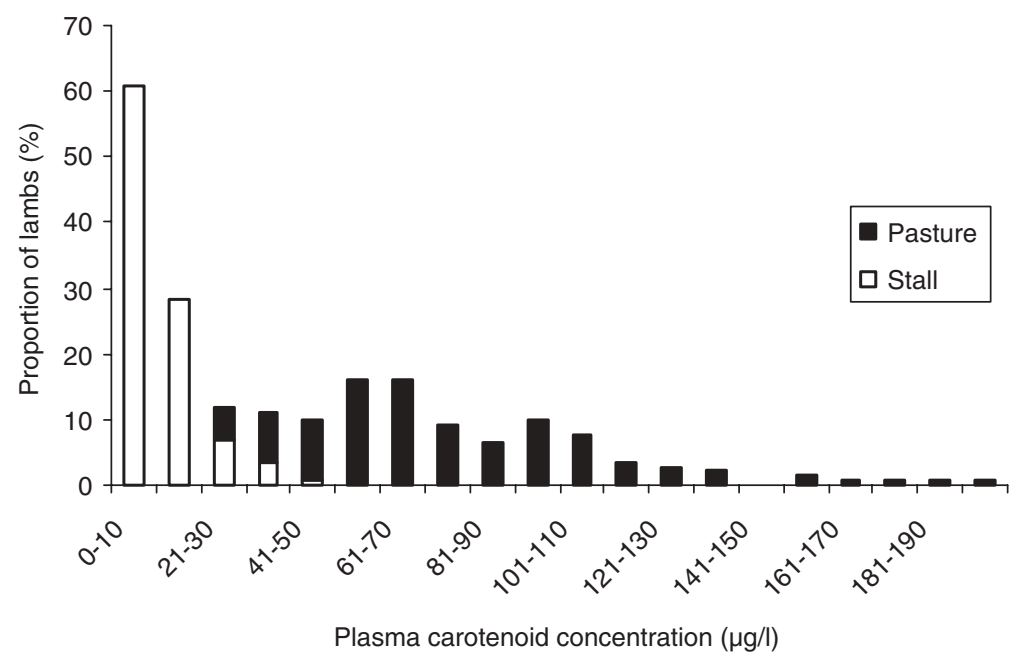

Figure 1 Frequency distribution of plasma carotenoid concentration at slaughter in pasture-fed and stall-fed lambs.
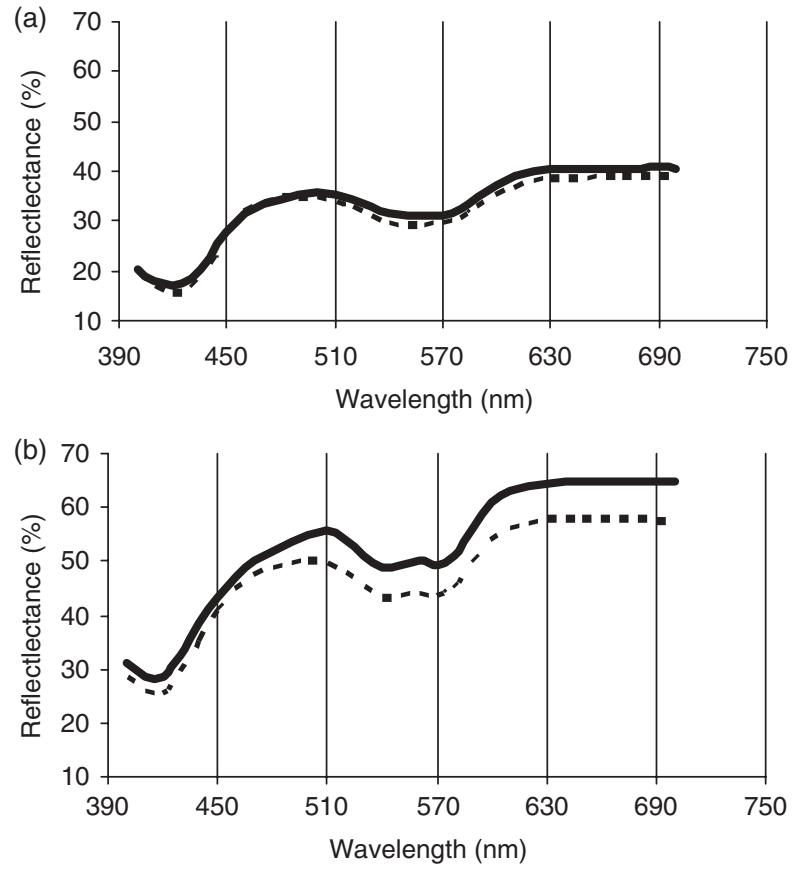

Figure 2 Mean reflectance spectrum of perirenal fat. Pasture-fed lambs (-) v. stall-fed lambs (---). Measurements made (a) at slaughter and (b) $24 \mathrm{~h}$ post mortem.

whereas it averaged only 10 (s.d. 8.5) $\mu \mathrm{g} / \mathrm{l}$ for $\mathrm{S}$ lambs, ranging from 0 to $43 \mu \mathrm{g} / \mathrm{l}$ (Figure 1). The proportion of P lambs with PCCS greater than or equal to $43 \mu \mathrm{g} / \mathrm{l}$ was $83.8 \%$, whereas the PCCS in $99.1 \%$ of the S lambs did not even reach this threshold. This threshold therefore allowed for the correct discrimination of $90.7 \%$ of the plasma samples.

Reflectance spectrum of the fat

Reflectance spectra of the fat from $P$ and $S$ lambs are reported in Figures 2 and 3 for measurements made on perirenal and subcutaneous caudal fat, respectively. All
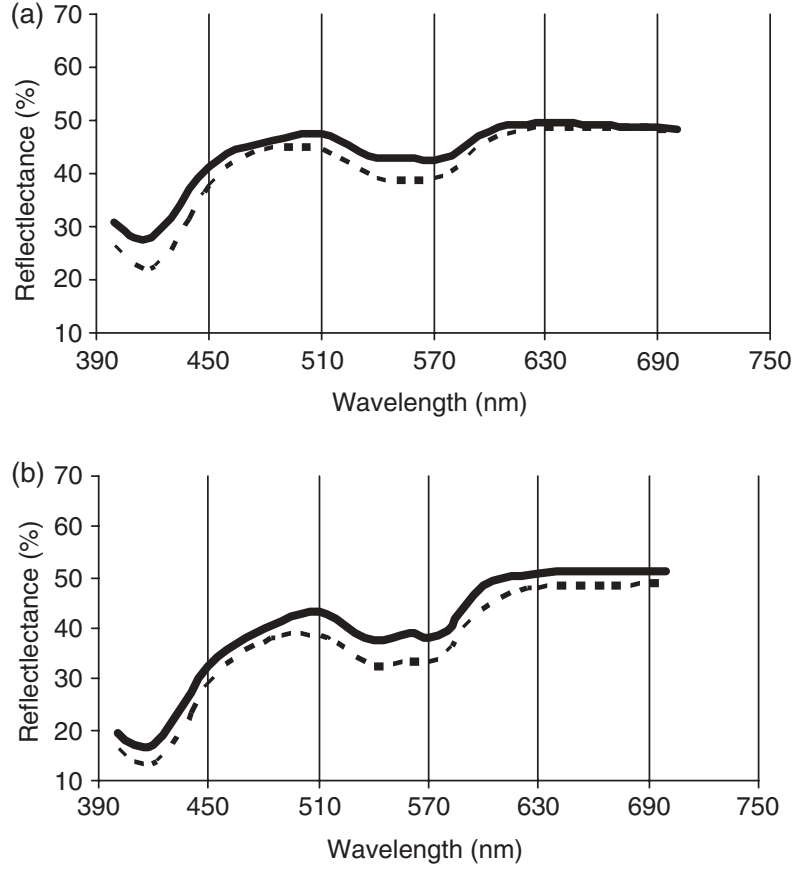

Figure 3 Mean reflectance spectrum of subcutaneous caudal fat. Pasture-fed lambs (-) v. stall-fed lambs (--). Measurements made (a) at slaughter and (b) $24 \mathrm{~h}$ post mortem.

spectra showed peaks at 410 to $420 \mathrm{~nm}$ wavelengths. The spectra generally showed absorbance at wavelengths $540 \mathrm{~nm}$ and 570 to $580 \mathrm{~nm}$, except for the spectra for perirenal fat at slaughter where absorbance occurred at $555 \mathrm{~nm}$ for both feeding treatments. The P samples generally showed lower absorbance than $S$ samples throughout the full visible spectrum. The shape of the reflectance spectra also differed between $P$ and $S$ in the area of light absorption by carotenoid pigments. The first derivative of the reflectance spectrum (illustrated in Figure 4 for perirenal fat at $24 \mathrm{~h}$ post mortem) was actually higher for $\mathrm{P}$ lambs than for $S$ lambs at wavelengths between 510 and 480 . 
Reflectance spectrum of the fat at wavelengths between 450 and $510 \mathrm{~nm}$ (method 1). The first method tested quantifies light absorption by the carotenoid pigments stored in the fat, using the shape of the reflectance spectrum at wavelengths between 450 and $510 \mathrm{~nm}$.

Mean $I_{450-510}$ of perirenal fat at slaughter was significantly different between $P$ and $S$ lambs $(P<0.001)$, averaging -112.31 and -28.81 units for $P$ and $S$ lambs, respectively. It ranged from -300.05 to 30.77 units for $P$ lambs and from -156.85 to 54.27 units for $S$ lambs. The frequency distribution of $P$ and $S$ lambs in the different classes of $I_{450-510}$ values measured on perirenal fat at slaughter is reported in Figure $5 \mathrm{a}$. The proportion of $\mathrm{P}$ lambs with a mean $I_{450-510}$ greater than or equal to -70 units was $28.7 \%$, whereas the proportion of $S$ lambs with a mean $I_{450-510}$ lower than -70 units was $13.4 \%$. This threshold therefore allowed for the correct classification of $79.5 \%$ of the lambs when the measurement was made on perirenal fat at slaughter.

Mean $I_{450-510}$ of perirenal fat measured $24 \mathrm{~h}$ post mortem was significantly different between $\mathrm{P}$ and $\mathrm{S}$ lambs $(P<0.001)$, averaging -265.32 and -128.65 units for $P$ and $S$ lambs, respectively. It ranged from -487.97 to -78.85 units for $P$ lambs and from -283.27 to -8.37

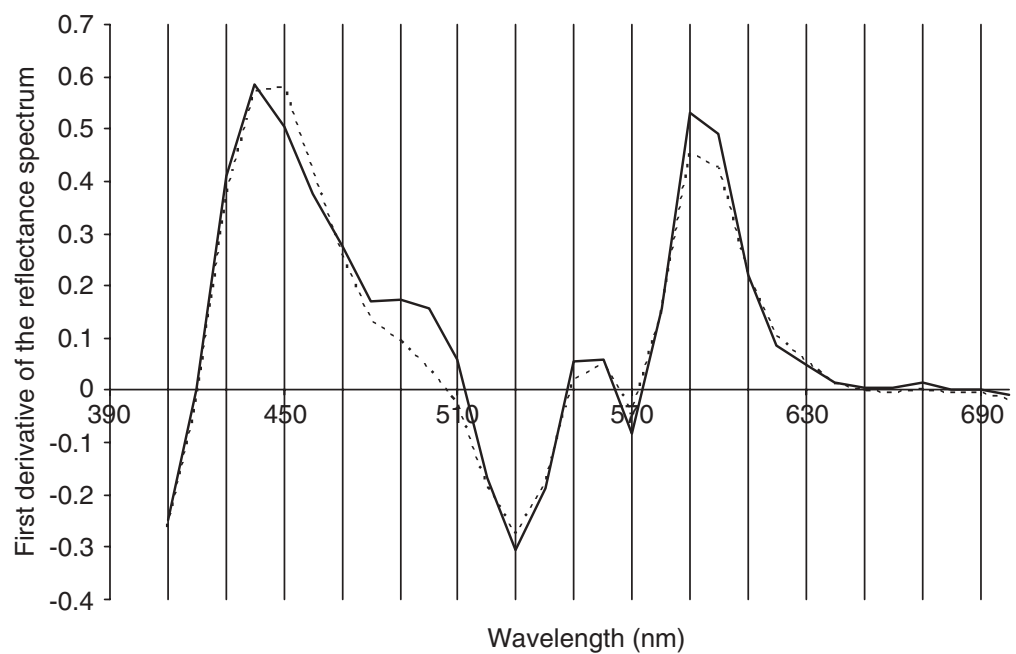

Figure 4 First derivative of the reflectance spectrum of perirenal fat. Pasture-fed lambs $(-)$ v. stall-fed lambs (---). Measurements made $24 \mathrm{~h}$ post mortem. First derivative at wavelength $410 \mathrm{~nm}$ is calculated as follows: (reflectance value at wavelength $410 \mathrm{~nm}$-reflectance value at wavelength $400 \mathrm{~nm}) / 10$
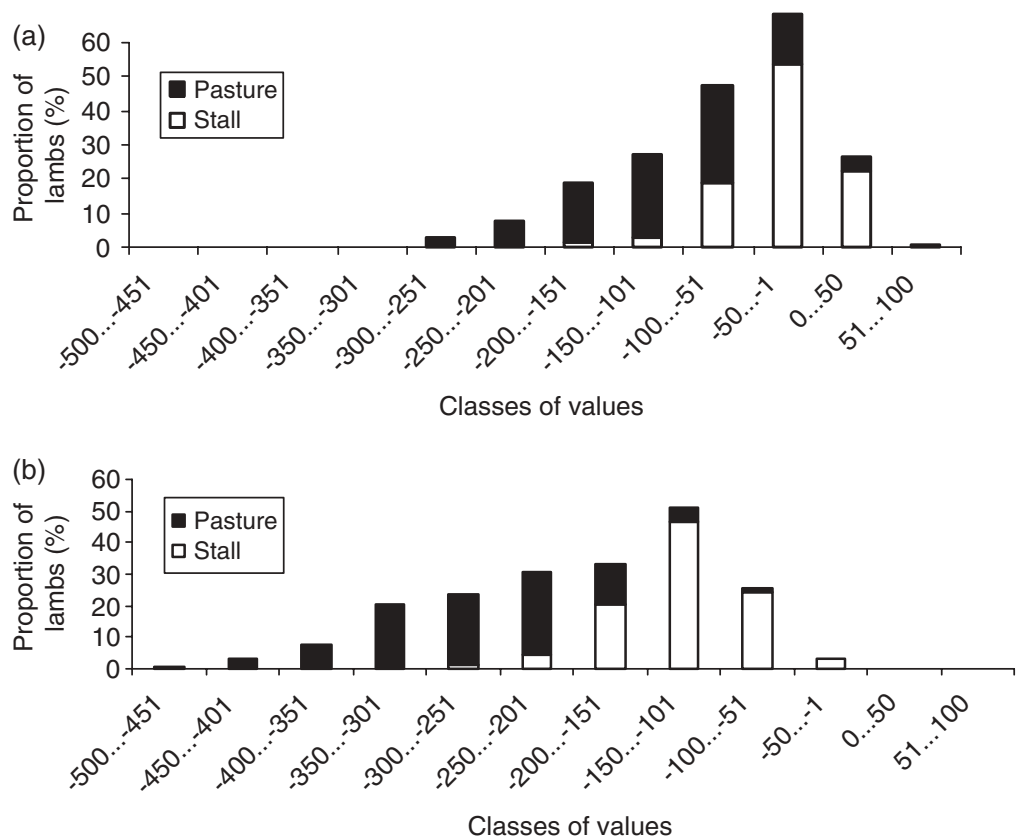

Figure 5 Frequency distribution of the pasture-fed and stall-fed lambs in the different classes of the integral value from the translated spectrum of perirenal fat between 450 and $510 \mathrm{~nm}\left(I_{450-510}\right)$. Measurements made (a) at slaughter and (b) $24 \mathrm{~h}$ post mortem. 

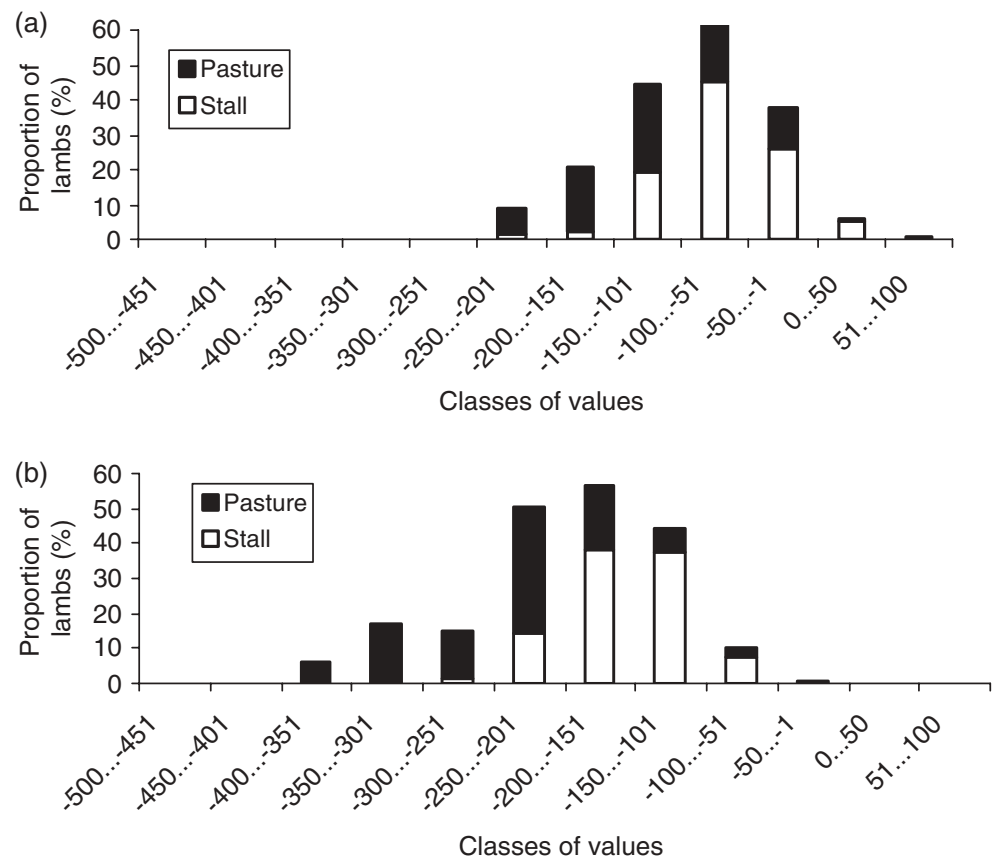

Figure 6 Frequency distribution of the pasture-fed and stall-fed lambs in the different classes of the integral value from the translated spectrum of subcutaneous caudal fat between 450 and $510 \mathrm{~nm}\left(I_{450-510}\right)$. Measurements made (a) at slaughter and (b) $24 \mathrm{~h}$ post mortem.

units for $\mathrm{S}$ lambs. The frequency distribution of $\mathrm{P}$ and $\mathrm{S}$ lambs in the different classes of $I_{450-510}$ values measured on perirenal fat $24 \mathrm{~h}$ post mortem is reported in Figure $5 \mathrm{~b}$. The proportion of $\mathrm{P}$ lambs with a mean $I_{450-510}$ greater than or equal to -197 units was $17.5 \%$, whereas the proportion of $S$ lambs with a mean $I_{450-510}$ lower than -197 units was $6.1 \%$. This threshold therefore allowed for the correct classification of $88.6 \%$ of the lambs when the measurement was made on perirenal fat $24 \mathrm{~h}$ post mortem.

Mean $I_{450-510}$ of subcutaneous caudal fat at slaughter was significantly different between $P$ and $S$ lambs $(P<0.001)$, averaging -111.69 and -69.55 units for $P$ and $S$ lambs, respectively. It ranged from -248.15 to -0.43 units for $P$ lambs and from -228.62 to 66.77 units for $\mathrm{S}$ lambs. The frequency distribution of $\mathrm{P}$ and $\mathrm{S}$ lambs in the different classes of $I_{450-510}$ values measured on subcutaneous caudal fat at slaughter is reported in Figure 6 a. The proportion of $\mathrm{P}$ lambs with a mean $I_{450-510}$ greater than or equal to -90 units was $41.3 \%$, whereas the proportion of $S$ lambs with a mean $I_{450-510}$ lower than -90 units was $29.9 \%$. This threshold therefore allowed for the correct classification of $64.8 \%$ of the lambs when the measurement was made on subcutaneous caudal fat at slaughter.

Mean $I_{450-510}$ of subcutaneous caudal fat $24 \mathrm{~h}$ post mortem was significantly different between $\mathrm{P}$ and $\mathrm{S}$ lambs $(P<0.001)$, averaging -236.88 and -155.39 units for $P$ and $S$ lambs, respectively. It ranged from -381.60 to -51.12 units for $P$ lambs and from -289.23 to -36.47 units for $S$ lambs. The frequency distribution of $P$ and $S$ lambs in the different classes of $I_{450-510}$ values measured on subcutaneous caudal fat $24 \mathrm{~h}$ post mortem is reported in Figure $6 \mathrm{~b}$. The proportion of $\mathrm{P}$ lambs with a mean $I_{450-510}$

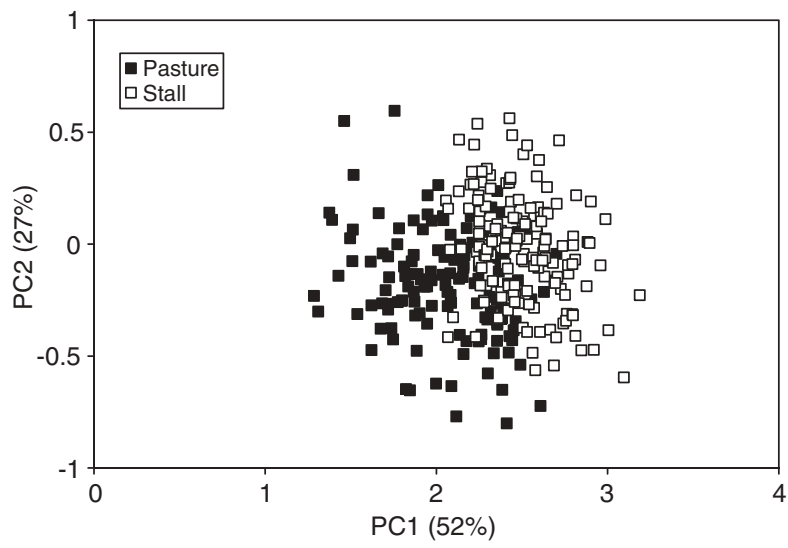

Figure 7 Score plot of the PC1 and PC2 axes for perirenal fat samples measured $24 \mathrm{~h}$ post mortem according to feeding treatment (black and white symbols refer to pasture-fed and stall-fed lambs, respectively).

greater than or equal to -196 units was $25.2 \%$, whereas the proportion of $S$ lambs with a mean $I_{450-510}$ lower than -196 units was $17.1 \%$. This threshold therefore allowed for the correct classification of $79.2 \%$ of the lambs when the measurement was made on subcutaneous caudal fat $24 \mathrm{~h}$ post mortem.

Reflectance spectrum at wavelengths between 400 and $700 \mathrm{~nm}$ (method 2). Method 2 utilised all the reflectance spectrum optical data for wavelengths between 400 and $700 \mathrm{~nm}$.

More than $90 \%$ of the total variance of the reflectance data for all 307 lambs was explained by the three first principal components (PC) axes regardless of site or time of 
Visible spectroscopy for diet authentication

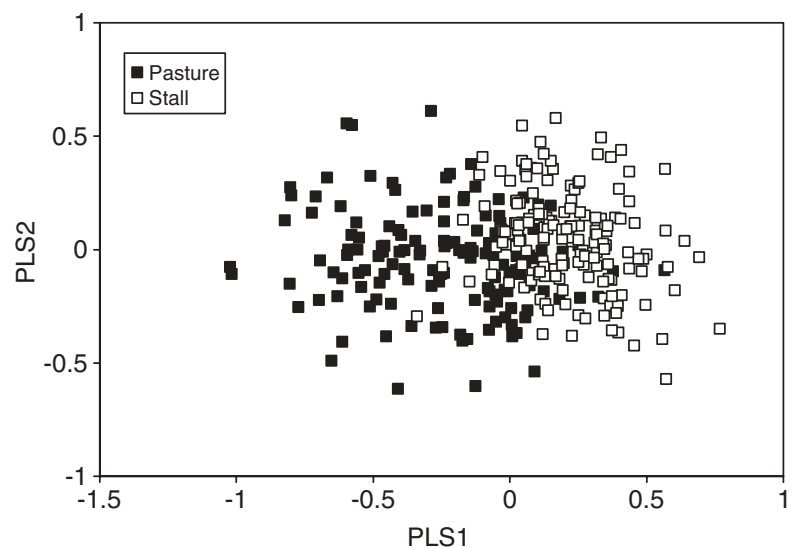

Figure 8 Score plot of the two first partial least square (PLS) factors for perirenal fat samples measured $24 \mathrm{~h}$ post mortem according to feeding treatment (black and white symbols refer to pasture-fed and stall-fed lambs, respectively).

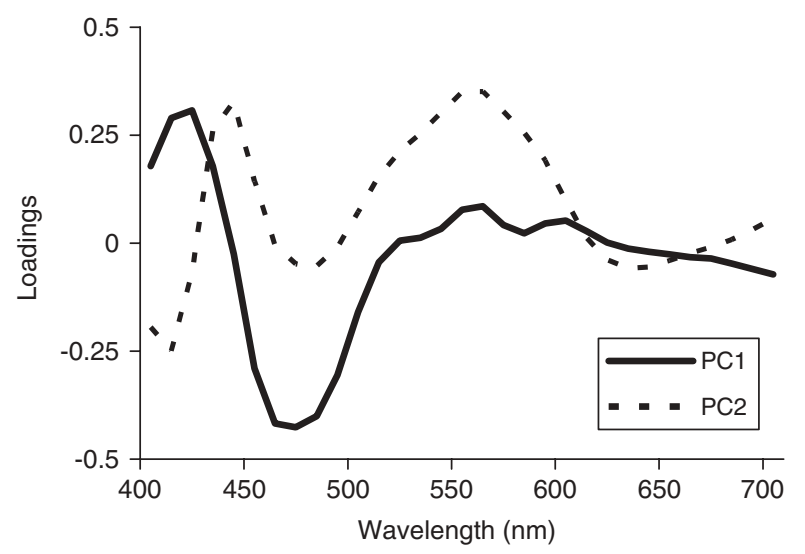

Figure 9 Loadings for the first two principal components axes for perirenal fat samples measured $24 \mathrm{~h}$ post mortem.

measurement. The score plots of the first two PC axes and of the first two factors of the PLS-DA model for perirenal fat measured at $24 \mathrm{~h}$ post mortem are shown in Figures 7 and 8 , respectively. PC1 and PC2 axes explained $52 \%$ and $27 \%$ of variability, respectively. The PCA loadings of the two PC axes for perirenal fat measured at $24 \mathrm{~h}$ post mortem are shown in Figure 9; the highest loading was situated around 460 to $480 \mathrm{~nm}$ for PC1. The PLS-DA loadings (data not shown) were similar to those observed in the PC analysis.

The statistical results generated by PLS-DA models are shown in Table 5. The PLS-DA analysis allowed for the correct classification of $79.7 \%$ and $95.1 \%$ of the $\mathrm{P}$ and $\mathrm{S}$ lambs, respectively (i.e. $87.4 \%$ on average), when the measurement was made on perirenal fat at slaughter, and $90.2 \%$ and $97.6 \%$ of the $P$ and $S$ lambs, respectively (i.e. $93.9 \%$ on average), when the measurement was made on perirenal fat $24 \mathrm{~h}$ post mortem. This method correctly classified $94.4 \%$ and $91.5 \%$ of the $\mathrm{P}$ and $\mathrm{S}$ lambs, respectively (i.e. $92.9 \%$ on average), when the measurement was made on subcutaneous fat at slaughter, and $88.1 \%$ and $93.9 \%$ of the $\mathrm{P}$ and $\mathrm{S}$ lambs, respectively (i.e.
Table 5 Statistical results from the PLS-DA models for classifying perirenal and caudal fat samples measured at slaughter or $24 \mathrm{~h}$ post mortem according to feeding treatment ${ }^{t}$

\begin{tabular}{lcccc}
\hline \hline & SECV & $R^{2}$ & $n$ & $\%$ CCS \\
\hline Perirenal fat at slaughter & 0.31 & 0.61 & 6 & 87.4 \\
Perirenal fat at 24h post mortem & 0.29 & 0.66 & 6 & 93.9 \\
Caudal fat at slaughter & 0.29 & 0.64 & 6 & 92.9 \\
Caudal fat at 24h post mortem & 0.32 & 0.58 & 6 & 91.0 \\
\hline
\end{tabular}

${ }^{\dagger}$ Abbreviations are: PLS-DA = partial least squares discriminant analysis; $\mathrm{SECV}=$ standard error of cross-validation; $R^{2}=$ coefficient of determination in cross-validation; $n=$ number of factors used in the PLS-DA calibration model; \% CCS = proportion of correctly classified samples.

$91.0 \%$ on average), when the measurement was made on subcutaneous fat $24 \mathrm{~h}$ post mortem.

Comparison between both reflectance methods applied on fat. Method 2, which used all the reflectance spectrum data at wavelengths between 400 to 700 , showed a higher performance $(P<0.001)$ than method 1 , which only used the reflectance spectrum data at wavelengths ranging from 450 to $510 \mathrm{~nm}$ to calculate $I_{450-510}$. Taking both sites, both measurement times and both feeding treatments together, the overall proportion of correctly classified lambs was actually $77.6 \%$ for method 1 and $91.3 \%$ for method 2 .

The proportion of correctly classified lambs also differed between feeding treatments $(80.0 \%$ and $88.9 \%$ for $\mathrm{P}$ and $\mathrm{S}$ lambs respectively, $P<0.001)$, measurement sites $(87.1 \%$ and $81.8 \%$ for perirenal and subcutaneous caudal fat, respectively, $P<0.001)$ and measurement times $(80.9 \%$ and $88.0 \%$ for measurements made at slaughter and $24 \mathrm{~h}$ post mortem, respectively, $P<0.001)$. There were significant interactions between experimental factors. Figures 10 and 11 show the results obtained for $P$ and $S$ lambs using both methods applied on perirenal and subcutaneous fat at slaughter and $24 \mathrm{~h}$ post mortem. For $\mathrm{P}$ lambs, using method 2 yielded a higher proportion of correctly classified lambs compared with method 1 (from 7.7 to 35.7 points, $P<0.05$ to 0.001$)$. For $S$ lambs, method 2 yielded a higher proportion of correctly classified lambs compared with method 1 (from 8.5 to 21.3 points, $P<0.001$ ), except for the measurements made at $24 \mathrm{~h}$ post mortem on perirenal fat, where the results of the two methods were not significantly different $(93.9 \%$ and $97.6 \%$ for methods 1 and 2 respectively, i.e. $P>0.05)$. The greatest difference between methods occurred for the measurement made at slaughter on the subcutaneous caudal fat of $P$ lambs, where the proportion of correctly classified lambs was only $58.7 \%$ with method 1, compared with $94.4 \%$ with method 2 .

\section{Discussion}

Plasma carotenoid concentration

This study confirmed that carotenoid pigments can be used to discriminate pasture-fed from stall-fed lambs, which is in 
Dian, Andueza, Barbosa, Amoureux, Jestin, Carvalho, Prado and Prache

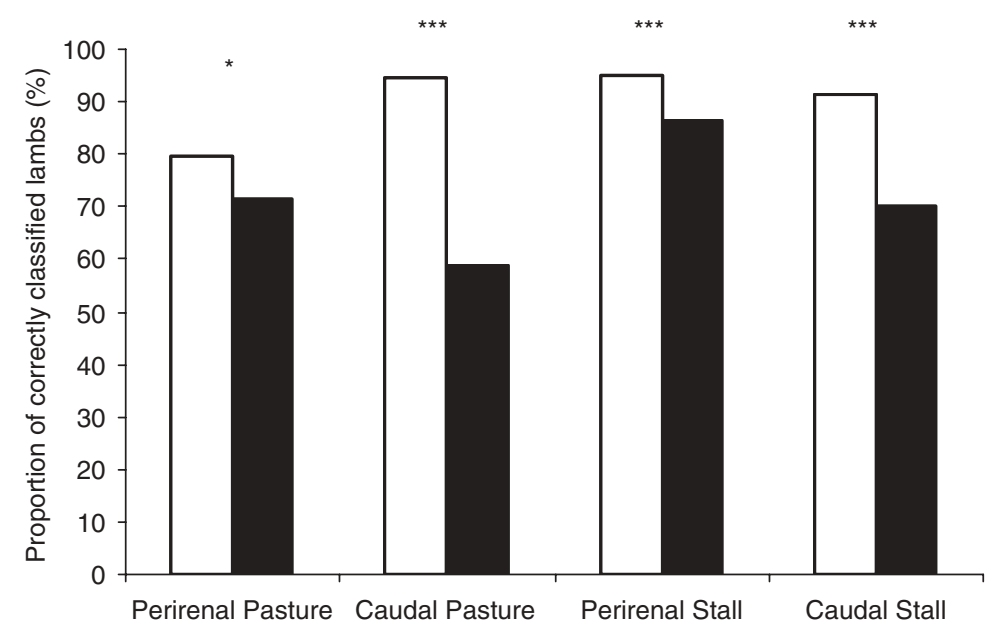

Figure 10 Proportion of correctly classified lambs using method 1 (integral value $I_{450-510}$, black symbols) and method 2 (full reflectance spectrum data sets at wavelengths between 400 and $700 \mathrm{~nm}$, white symbols) on perirenal and subcutaneous caudal fat measured at slaughter. Perirenal Pasture, caudal Pasture, perirenal Stall and caudal Stall refer to measurements made on perirenal fat from pasture-fed lambs, on subcutaneous caudal fat from pasture-fed lambs, on perirenal fat from stall-fed lambs and on subcutaneous caudal fat from stall-fed lambs, respectively. ${ }^{*},{ }^{* *},{ }^{* *}$ : the proportion was significantly different between methods at $P<0.05, P<0.01$ and $P<0.001$, respectively.

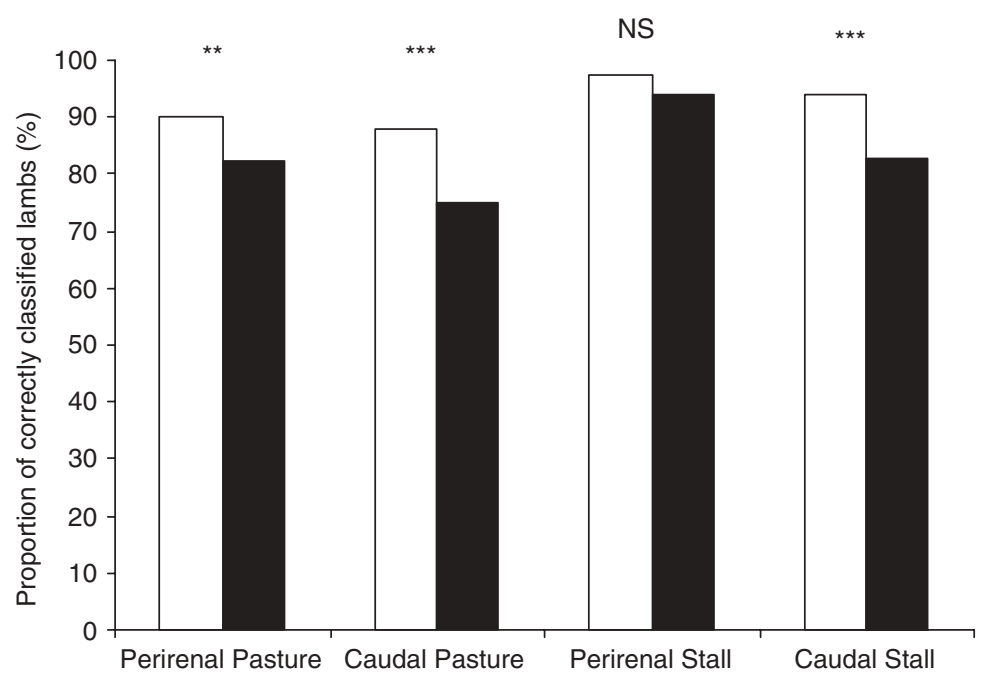

Figure 11 Proportion of correctly classified lambs using method 1 (integral value $I_{450-510}$, black symbols) and method 2 (full reflectance spectrum data sets at wavelengths between 400 and $700 \mathrm{~nm}$, white symbols) on perirenal and subcutaneous caudal fat measured $24 \mathrm{~h}$ post mortem. Perirenal Pasture, caudal Pasture, perirenal Stall and caudal Stall refer to measurement made on perirenal fat from pasture-fed lambs, on subcutaneous caudal fat from pasture-fed lambs, on perirenal fat from stall-fed lambs and on subcutaneous caudal fat from stall-fed lambs, respectively. ${ }^{*},{ }^{* *},{ }^{* *}$ : the proportion was significantly different between methods at $P<0.05, P<0.01$ and $P<0.001$, respectively.

line with previous studies (Prache et al., 2003a). PCCS allowed for the correct discrimination of feeding treatments for $90.7 \%$ of the plasma samples. The quality of the discrimination was lower than that reported in Prache et al. (2003a), where there was no overlapping in the frequency distribution of the PCCS of pasture-fed lambs and stall-fed lambs, although the mean values were similar between both studies ( 75 and $10 \mu \mathrm{g} / \mathrm{l}$ for $P$ and $S$ lambs, respectively, in this study, compared with 63 and $12 \mu \mathrm{g} / \mathrm{l}$ for $\mathrm{P}$ and $S$ lambs, respectively, in Prache et al., 2003a). The discrimination quality differences between studies are probably due to differences in between-sample variability, with PCCS ranging from 27 to $194 \mu \mathrm{g} / \mathrm{l}$ for $\mathrm{P}$ lambs and from 0 to $43 \mu \mathrm{g} / \mathrm{l}$ for $S$ lambs in this study, compared with 37 to
$105 \mu \mathrm{g} / \mathrm{l}$ for $\mathrm{P}$ lambs and 6 to $21 \mu \mathrm{g} / \mathrm{l}$ for $S$ lambs in Prache et al. (2003a). Possible explanations for this variability are variability in carotenoid intake level and between-animal variability in carotenoid absorption and metabolism. Carotenoid intake level probably varies with carotenoid concentration in the herbage, which may have varied widely in this study, since blood samples were collected from the beginning of August to the beginning of November, compared with from the end of July to the end of August in Prache et al. (2003a). However, we still observed a broad variability among animals at any given date, despite the fact that the lambs were grazing the same paddock. This may have been due to inter-individual variations in forage intake levels and in carotenoid absorption and metabolism 
(Rock, 1997). On heterogeneous swards, variations can also be due to inter-individual variability in dietary choices (Prache and Damasceno, 2006).

\section{Reflectance spectrum at wavelengths between 450 and $510 \mathrm{~nm}$}

Perirenal fat. Discrimination between feeding treatments using perirenal fat $I_{450-510}$ was more reliable when measurements were made $24 \mathrm{~h}$ post mortem (88.6\%) than at slaughter (79.5\%). This is in disagreement with the results of Priolo et al. (2002), who reported lower discrimination reliability $24 \mathrm{~h}$ post mortem than at slaughter when using the same method. This discrepancy may be due to the fact that we cut a flat surface on the fat before the measurements to ensure a perfect adherence of the eye of the apparatus, whereas this was not done in Priolo et al. (2002).

Subcutaneous caudal fat. Discrimination between feeding treatments using subcutaneous caudal fat $I_{450-510}$ was more reliable when measurements were made $24 \mathrm{~h}$ post mortem $(79.2 \%)$ than at slaughter $(64.8 \%)$. These results are in agreement with Priolo et al. (2002), who reported higher discrimination reliability $24 \mathrm{~h}$ post mortem than at slaughter.

The results from the present study therefore confirm that perirenal fat is better than subcutaneous caudal fat for discriminating pasture-fed from stall-fed lambs based on the quantification of light absorption by carotenoid pigments at wavelengths ranging from 450 to $510 \mathrm{~nm}$ of the reflectance spectrum. The greater reliability after $24 \mathrm{~h}$ of cooling is likely to be due to an increase in fat-based carotenoid concentration due to water evaporation. The quality of the discrimination was, however, lower in this study than in the previous studies by Priolo et al. (2002) and Prache et al. (2003b). This may be due to variations across breeds (Limousine breed used in this study whereas Priolo et al., 2002 and Prache et al., 2003b used the lle de France breed), as animal tissues may store different amounts of carotenoid pigments depending on the breed (Nozière et al., 2006). It may also be due to a higher variability in the carotenoid concentration of the herbage and (or) to a higher betweenanimal variability, given the large number of animals used in the present study (143 P and $164 \mathrm{~S}$ Limousine lambs) compared with the previous studies with lle de France lambs (24 P and $24 \mathrm{~S}$ lle de France lambs, after pooling the data from Priolo et al., 2002 and Prache et al., 2003b together). This large between-animal variability highlights the essential role of the validation procedures on large number of animals. Given that the tendency to accumulate carotenoids has a genetic component (Sheath et al., 2001), the range of variation of the plasma carotenoid concentration and of $I_{450-510}$ in $\mathrm{P}$ and $\mathrm{S}$ lambs probably varies across breeds. The reliability of the corresponding methods for discriminating $\mathrm{P}$ and $\mathrm{S}$ lambs in different breeds therefore requires further experimental evaluation. Consequently, we have launched a validation procedure with a large cohort of animals of different breeds soundly to assess variability within and across breeds.

\section{Reflectance spectrum at wavelengths between 400 and $700 \mathrm{~nm}$}

The main result of this study is that taking all the reflectance spectral data within the wavelengths range 400 to $700 \mathrm{~nm}$ into account improves the reliability of the discrimination based on the fat reflectance spectrum. Performing discriminant analysis on all the optical data generated at wavelengths between 400 and $700 \mathrm{~nm}$ made it possible to correctly classify $87.4 \%$ of the perirenal fat samples and $92.9 \%$ of the subcutaneous fat samples when measurements were made at slaughter, and $93.9 \%$ of the perirenal fat samples and $91.0 \%$ of the subcutaneous fat samples when measurements were made $24 \mathrm{~h}$ post mortem. The improvement in discrimination reliability was therefore greater for subcutaneous than for perirenal fat, and for measurements made at slaughter compared with those made $24 \mathrm{~h}$ post mortem. The underlying mechanisms involved remain an open question. The differences in the shape of the reflectance spectrum between $P$ and $S$ lambs at wavelengths between 450 and $510 \mathrm{~nm}$, and the loading values of the PC1 axis in this area clearly underline the importance of carotenoid pigments in discriminating between $\mathrm{P}$ and $\mathrm{S}$ lambs. Beyond carotenoid pigments, the visible region is also characteristic for the respiratory pigments, whose absorption bands in the fat reflectance spectrum (Soret band at wavelengths 415 to $435 \mathrm{~nm}$, absorption bands at wavelengths 540 to $580 \mathrm{~nm}$ ) are probably linked to residual haemoglobin after slaughter (Swatland, 1989; Prache et al., 1990; Irie, 2001). In haemoglobin derivates, the absorbance bands are located at wavelengths 430 and $555 \mathrm{~nm}$ for deoxyhaemoglobin and 418,540 to 542 and 576 to $578 \mathrm{~nm}$ for oxyhaemoglobin, the loss of oxygen being associated with a shift in the Soret band to a slightly higher wavelength and the loss of the bicuspid shape of the secondary peak around $555 \mathrm{~nm}$ (Irie, 2001). The $P C 1$ and $P C 2$ axis loading values at wavelengths around 410 to 420,440 and $560 \mathrm{~nm}$ may indicate that haem pigments could also be involved in the discrimination between $\mathrm{P}$ and $\mathrm{S}$ lambs.

\section{Conclusions}

Research on diet authentication in herbivore products is conducted within a general context of increasing consumer concern regarding the mode of animal production. This study reports methodological developments in the use of visible reflectance spectroscopy for discriminating between carcasses from pasture-fed or concentrate-fed lambs. The main result is that the reliability of the discrimination between pasture-fed and stall-fed lambs based on the fat reflectance spectrum was generally higher when using the full set of optical data at wavelengths between 400 and $700 \mathrm{~nm}$ than when only quantifying light absorption at 
wavelengths ranging from 450 to $510 \mathrm{~nm}$, as previously proposed in the literature. The proportion of lambs correctly classified via multivariate analysis factoring in the full set of optical data at wavelengths between 400 and $700 \mathrm{~nm}$ was $87.4 \%$ and $92.9 \%$ for measurements made on perirenal and caudal fat at slaughter, and $93.9 \%$ and $91.0 \%$ for measurements made on perirenal and caudal fat at $24 \mathrm{~h}$ post mortem. This methodological development is of practical interest because the measurement can still be made quickly to keep in pace with processing lines in commercial slaughterhouses. This study also confirmed that plasma carotenoid concentration can be used to discriminate pasture-fed from stall-fed lambs, as it enabled the correct classification of $90.7 \%$ of lambs. Future research will be targeted at evaluating these methods in different feeding conditions in interaction with animal characteristics.

\section{Acknowledgements}

We thank J. Ballet, R. Jailler, J. Pourrat, and all the staff of the INRA, UE1153 Unité Expérimentale des Mont Dore and the Abattoir staff for their cooperation on the study. We also thank P. Gasqui for valuable advice on data analysis. P.H.M. Dian thanks the Brazilian Ministry of the Education 'Coordenação de Aperfeiçoamento de Pessoal de Nível Superior' (CAPESPDEE) for financial assistance given under a doctoral grant.

\section{References}

Aurousseau B, Bauchart D, Calichon E, Micol D and Priolo A 2004. Effect of grass or concentrate feeding systems and rate of growth on triglyceride and phospholipid and their fatty acids in the $m$. longissimus thoracis of lambs. Meat Science 66, 531-541.

Cardinault N, Doreau M, Poncet C and Nozière P 2006. Digestion and absorption of carotenoids in sheep fed fresh red clover. Animal Science 82, 49-55.

Daget $P$ and Poissonnet $P$ 1971. Une méthode d'analyse phytosociologique des prairies. Critères d'application. Annales Agronomiques 22, 5-41.

Enser M, Hallett KG, Hewett B, Fursey GAJ, Wood JD and Harrington G 1998. Fatty acid content and composition of UK beef and lamb muscle in relation to production system and implications for human nutrition. Meat Science 49, 329-341.

Fisher AV and de Boer H 1994. The EAAP standard method of sheep carcass assessment. Carcass measurements and dissection procedures report of the EAAP working group on carcass evaluation, in cooperation with the CIHEAM Instituto Agronomico Mediterraneo of Zaragoza and the CEC Directorate General for Agriculture in Brussels. Livestock Production Science 38, 149-159. Irie M 2001. Optical evaluation of factors affecting appearance of bovine fat. Meat Science 57, 19-22.

Karijord 0 1978. Correlation between the concentration of carotenoids in depot fat and in plasma of sheep. Acta Agriculturae Scandinavica 28, 355-359.

Kirton AH, Grane B, Paterson DJ and Clare NT 1975. Yellow fat in lambs caused by carotenoid pigmentation. New Zealand Journal of Agricultural Research 18, 267-272.
Lyan B, Azais-Braesco V, Cardinault N, Tyssandier V, Borel P, AlexandreGouabau MC and Grolier P 2001. Simple method for clinical determination of 13 carotenoids in human plasma using an isocratic high-performance liquid chromatographic method. Journal of Chromatography B: Biomedical Sciences and Applications 751, 297-303.

Martin B, Cornu A, Kondjoyan N, Ferlay A, Verdier-Metz I, Pradel P, Rock E, Chilliard Y, Coulon JB and Berdagué JL 2005. Milk indicators for recognizing the types of forages eaten by dairy cows. In Indicators of milk and beef quality (ed. JF Hocquette and S Gigli), EAAP publication 112, pp. 127-136. Wageningen Academic Publishers, Wageningen, NL.

Nozière P, Graulet B, Lucas A, Martin B, Grolier P and Doreau M 2006. Carotenoids in ruminants: from forages to dairy products. Animal Feed Science and Technology 131, 418-450.

Nürnberg K, Grumbach S, Zupp W, Hartung M, Nürnberg G and Ender K 2001. Enhancing of $n-3$ fatty acids and conjugated fatty acid in lamb meat by keeping on pasture. Fleishwirtschaft 81, 120-122.

Patterson DSP 1965. The association between depot fat mobilization and the presence of xanthophyll in the plasma of normal sheep. Journal of Agricultural Science 64, 273-278.

Prache S and Thériez M 1999. Traceability of lamb production systems: carotenoids in plasma and adipose tissue. Animal Science 69, 29-36.

Prache S and Damasceno JC 2006. Preferences of sheep grazing down conterminal monocultures of Lolium perenne-Festuca arundinacea: test of an energy intake-rate maximisation hypothesis using the short-term double weighing technique. Applied Animal Behaviour Science 97, 206-220.

Prache S, Aurousseau B, Thériez M and Renerre M 1990. Les défauts de couleur du tissu adipeux sous-cutané des carcasses d'ovins. INRA Productions Animales 3, 275-285.

Prache S, Priolo A, Tournadre H, Jailler R, Dubroeucq H, Micol D and Martin B 2002. Traceability of grass feeding by quantifying the signature of carotenoid pigments in herbivore meat, milk and cheese. Proceedings of the 19th general meeting of the European grassland federation (ed. JL Durand, JC Emile, C Huyghe and G Lemaire), pp. 592-593. Association Française pour la Production Fourragère (AFPF), La Rochelle, France.

Prache S, Priolo A and Grolier P 2003a. Persistence of carotenoid pigments in the blood of concentrate-finished grazing sheep: its significance for the traceability of grass-feeding. Journal of Animal Science 81, 360-367.

Prache S, Priolo A and Grolier P 2003b. Effect of concentrate finishing on the carotenoid content of perirenal fat in grazing sheep: its significance for discriminating grass-fed, concentrate-fed and concentrate-finished grazing lambs. Animal Science 77, 225-233.

Prache S, Cornu A, Berdagué JL and Priolo A 2005. Traceability of animal feeding diet in the meat and milk of small ruminants. Small Ruminant Research 59, 157-168.

Priolo A, Prache S, Micol D and Agabriel J 2002. Reflectance spectrum to trace grass feeding in sheep: Influence of measurement site and shrinkage time after slaughter. Journal of Animal Science 80, 886-891.

Rock CL 1997. Carotenoids: biology and treatment. Pharmacology and Therapeutics 75, 185-197.

Russel AJF, Doney JM and Gunn RG 1969. Subjective assessment of body fat in live sheep. Journal Agricultural Science 72, 451-454.

Sheath GW, Coulon JB and Young OA 2001. Grassland management and animal product quality. Proceedings of the 19th international grassland congress on grassland ecosystems: an outlook into the 21st century (ed. JA Gomide, WRS Mattos and SC de Silva), pp. 1019-1026. Fundação de Estudos Agrários Luiz de Queiroz, Piracicaba, Brazil.

Statistical Analysis Systems Institute 1999. SAS/STAT user's guide version 8. SAS Institute Inc., Cary, NC.

Swatland HJ 1989. Carotene reflectance and the yellowness of bovine adipose tissue measured with a portable fibre-optic spectrophotometer. Journal of the Science of Food and Agriculture 46, 195-200. 